\title{
Role of Ryanodine and NMDA Receptors in Tetrabromobisphenol A-Induced Calcium Imbalance and Cytotoxicity in Primary Cultures of Rat Cerebellar Granule Cells
}

\author{
Elzbieta Zieminska $^{1} \cdot$ Aleksandra Stafiej $^{1} \cdot$ Beata Toczylowska $^{2,3} \cdot$ Jan Albrecht $^{4}$. \\ Jerzy W. Lazarewicz ${ }^{1}$
}

Received: 5 May 2015/Revised: 1 July 2015/Accepted: 10 July 2015/Published online: 28 July 2015

(C) The Author(s) 2015. This article is published with open access at Springerlink.com

\begin{abstract}
The study assessed the role of ryanodine receptors (RyRs) and NMDA receptors (NMDARs) in the $\mathrm{Ca}^{2+}$ transients and cytotoxicity induced in neurons by the brominated flame retardant tetrabromobisphenol A (TBBPA). Primary cultures of rat cerebellar granule cells (CGC) were exposed to $7.5,10$, or $25 \mu \mathrm{M}$ TBBPA for $30 \mathrm{~min}$, and cell viability was assessed after $24 \mathrm{~h}$. Moreover, ${ }^{45} \mathrm{Ca}$ uptake was measured, and changes in the intracellular $\mathrm{Ca}^{2+}$ concentration $\left(\left[\mathrm{Ca}^{2+}\right]_{\mathrm{i}}\right)$ were studied using the fluo-3 probe. The involvement of NMDARs and RyRs was verified using the pertinent receptor antagonists, $0.5 \mu \mathrm{M}$ MK-801 and $2.5 \mu \mathrm{M}$ bastadin 12 , which was coapplied with $200 \mu \mathrm{M}$ ryanodine, respectively. The results show that TBBPA concentration-dependently induces an increase in $\left[\mathrm{Ca}^{2+}\right]_{i}$. This effect was partly suppressed by the inhibitors of RyRs and NMDARs when administered separately, and completely abrogated by their combined application. A concentration-dependent activation of ${ }^{45} \mathrm{Ca}$ uptake by TBBPA was prevented by MK-801 but not by RyR inhibitors. Application of $\geq 10 \mu \mathrm{M}$ TBBPA concentration-dependently reduced neuronal viability, and this
\end{abstract}

Elzbieta Zieminska

elziem@imdik.pan.pl

1 Department of Neurochemistry, Mossakowski Medical Research Centre, Polish Academy of Sciences, Pawinskiego 5, 02-106 Warsaw, Poland

2 Institute of Biochemistry and Biophysics, Polish Academy of Sciences, Pawinskiego 5A, 02-106 Warsaw, Poland

3 Nalecz Institute of Biocybernetics and Biomedical Engineering, Polish Academy of Sciences, Trojdena 4, 02-109 Warsaw, Poland

4 Department of Neurotoxicology, Mossakowski Medical Research Centre, Polish Academy of Sciences, Pawinskiego 5, 02-106 Warsaw, Poland effect was only partially and to an equal degree reduced by NMDAR and RyR antagonists given either separately or in combination. Our results directly demonstrate that both the RyR-mediated release of intracellular $\mathrm{Ca}^{2+}$ and the NMDAR-mediated influx of $\mathrm{Ca}^{2+}$ into neurons participate in the mechanism of TBBPA-induced $\mathrm{Ca}^{2+}$ imbalance in CGC and play a significant, albeit not exclusive, role in the mechanisms of TBBPA cytotoxicity.

Keywords Brominated flame retardants - Calcium release $\cdot$ Neuronal culture $\cdot$ Excitotoxicity

\section{Introduction}

Tetrabromobisphenol A (TBBPA) belongs to a large group of brominated flame retardants (BFRs) that are heat-resistant and decrease the chance of ignition of electronic equipment, textiles, and building materials. The economic profits of the use of BFRs are overshadowed by potential environmental and toxicological hazards (Alaee and Wenning 2002; de Wit 2002; Williams and DeSesso 2010; Hendriks et al. 2014). Several studies have demonstrated pharmacological and toxic properties of TBBPA, including endocrine-disrupting activity, immunotoxicity, and neurotoxicity (Kitamura et al. 2005; Nakajima et al. 2009; Reistad et al. 2005, 2007; Hendriks et al. 2014).

Several putative mechanisms of TBBPA neurotoxicity have been proposed. TBBPA inhibits the activity of nicotinic acetylcholine receptors and stimulates GABA receptors (Hendriks et al. 2012); moreover, TBBPA modulates intracellular signaling independently of cell membrane receptor activation. TBBPA interferes with the activities of MAP and PKC kinases and of the ligand-activated transcription factor PPAR- $\gamma$, activates caspases, induces 
enhanced production of reactive oxygen species and $\beta$ amyloid and increases the intracellular concentration of $\mathrm{Ca}^{2+}\left(\left[\mathrm{Ca}^{2+}\right]_{\mathrm{i}}\right)$ (Canesi et al. 2005; Mariussen and Fonnum 2003; Nakajima et al. 2009; Ogunbayo et al. 2008; Reistad et al. 2005, 2007; Al-Mousa and Michelangeli 2012, 2014; Wojtowicz et al. 2014). In this study, we have focused on the latter phenomenon.

Reistad et al. (2007) described an increase in $\left[\mathrm{Ca}^{2+}\right]_{\mathrm{i}}$ and cytotoxicity in primary neuronal cultures challenged with TBBPA. The latter phenomenon was prevented by antagonists of NMDA receptors (NMDARs), which suggested that glutamate receptors can mediate these processes. Using the TM4 Sertoli cell line model, Ogunbayo et al. (2008) showed TBBPA-mediated mobilization of intracellular $\mathrm{Ca}^{2+}$ stores via ryanodine receptors (RyRs) and proposed a role of this effect in TBBPA cytotoxicity. Other studies revealed that in addition to intracellular $\mathrm{Ca}^{2+}$ release, TBBPA strongly inhibits the sarcoplasmic-endoplasmic reticulum $\mathrm{Ca}^{2+}$-ATPase (SERCA) and voltagesensitive $\mathrm{Ca}^{2+}$ channels (Ogunbayo and Michelangeli 2007; Al-Mousa and Michelangeli 2012, 2014; Hendriks et al. 2012, 2014).

Recently, we observed similarity in the $\mathrm{Ca}^{2+}$ release induced by $10 \mu \mathrm{M}$ TBBPA and $0.2 \mu \mathrm{M}$ thapsigargin in primary cultures of rat cerebellar granule cells (CGC) (Zieminska et al. 2014b). Both TBBPA- and thapsigarginevoked $\mathrm{Ca}^{2+}$ transients were sensitive to inhibition by $200 \mu \mathrm{M}$ ryanodine as long as the brominated tyrosine derivative bastadin 12 was present at a concentration of $2.5 \mu \mathrm{M}$, whereas ryanodine alone had a weak or no effect (Zieminska et al. 2014b).

Ryanodine is a selective ligand of RyRs, bidirectionally interfering with RyRs in a concentration-dependent way. At submicromolar concentrations, ryanodine binding results in half-opening of the receptor channel, leading to $\mathrm{Ca}^{2+}$ efflux from ER to the cytoplasm and to transient rise in $\left[\mathrm{Ca}^{2+}\right]_{\mathrm{i}}$, while at micromolar concentrations ryanodine closes RyRs (Fill and Copello 2002). Bastadins are cyclic derivatives of brominated tyrosine; many biologically active bastadins interfere with the formation of RyR-immunophilin FKBP12 complexes (Mack et al. 1994; Chen et al. 1999). Recently, we demonstrated that in CGC, the increase in $\left[\mathrm{Ca}^{2+}\right]_{\mathrm{i}}$ induced by $10 \mu \mathrm{M}$ TBBPA is resistant to inhibition by $200 \mu \mathrm{M}$ ryanodine, whereas its co-administration with $2.5 \mu \mathrm{M}$ bastadin 12 , which by itself has no effect on the level of $\mathrm{Ca}^{2+}$, completely inhibited TBBPA-evoked calcium transients (Zieminska et al. 2014b). Importantly, the combination of bastadin 5 or bastadin 12 with ryanodine also inhibits the intracellular $\mathrm{Ca}^{2+}$ release induced by thapsigargin or non-coplanar 2,2',3,5',6-pentachlorobiphenyl (PCB 95) (Mack et al. 1994; Gafni et al. 2004; Pessah et al. 2010; Zieminska et al. 2006a, b). These phenomena have been attributed to the conversion by these $\mathrm{Ca}^{2+}$ releasers of ryanodine-sensitive RyRs into leak channels, which are insensitive to ryanodine. In contrast, bastadins at low micromolar concentrations reverse this phenomenon and restore the sensitivity of RyRs to ryanodine (Pessah et al. 1997; Eltit et al. 2010; Altamirano et al. 2012).

While excessive mobilization of $\mathrm{Ca}^{2+}$ from endoplasmic reticulum stores by thapsigargin and other $\mathrm{Ca}^{2+}$ releasers has been implicated in their neurotoxicity (Silverstein and Nelson 1992; Pessah et al. 2010; Stirling et al. 2014), contrasting reports have appeared envisaging neuroprotective potential residing in the up-regulation of RyRs and in the ensuing increased release of $\mathrm{Ca}^{2+}$ from the ER (Supnet et al. 2010).These discrepant effects prompted us to consider bastadin 12 and ryanodine as pharmacological tools to get a deeper insight into the role of intracellular $\mathrm{Ca}^{2+}$ release by TBBPA via RyRs in cytotoxicity, which to our knowledge has not been directly tested in CGC or neurons cultured from any other brain region. In addition, we considered the putative role of NMDARs in the TBBPA-induced increases in $\left[\mathrm{Ca}^{2+}\right]_{\mathrm{i}}$ in neurons by triggering the influx of extracellular $\mathrm{Ca}^{2+}$, resulting in cytotoxicity. The role of NMDARs and $\mathrm{Ca}^{2+}$ in the mechanism of neuronal excitotoxicity is well known and the neuroprotective potential of MK-801 under these conditions has since long been recognized (Choi 1985; Szydlowska and Tymianski 2010).

The aim of the present study was to assess the role of $\mathrm{Ca}^{2+}$ release from intracellular stores and its influx via NMDARs in the mechanisms of TBBPA-induced $\mathrm{Ca}^{2+}$ imbalance and toxicity in neurons. In this study, we investigated the effects of the acute application of 7.5, 10, and $25 \mu \mathrm{M}$ TBBPA on changes in $\left[\mathrm{Ca}^{2+}\right]_{\mathrm{i}},{ }^{45} \mathrm{Ca}$ uptake from the incubation medium and cell survival in primary cultures of rat CGC. The modulators of the effects of TBBPA used in this study included the NMDAR antagonist MK-801 and the RyR antagonist ryanodine which was coapplied with bastadin 12 .

\section{Materials and Methods}

\section{Reagents}

Tetrabromobisphenol A (2,2-bis(4-hydroxy-3,5-dibromophenyl)propane, TBBPA) and 2,2',3,5',6-pentachlorobiphenyl (PCB 95) were obtained from LCG Standards Poland (Lomianki, Poland). L-Glutamate, ryanodine, (+)5-methyl-10,11-dihydro-5H-dibenzo[a,d]-cyclohepten-5,10imine hydrogen maleate (MK-801), dimethyl sulfoxide (DMSO), and propidium iodide, which were of analytical 
grade, as well as fetal bovine serum, cytosine $\beta$-D-arabinofuranoside, and the other materials for cell culturing were purchased from Sigma-Aldrich Chemical Poland (Poznań, Poland). Bastadin 12, which was provided by Dr. Emmanuel N. Pitsinos (Laboratory of Natural Products Synthesis and Bioorganic Chemistry, Institute of Bioorganic Chemistry NCRS "Demokritos" in Athens, Greece), was synthesized there according to the method of Couladouros et al. (2005). Fluo-3AM was purchased from Molecular Probes Inc. (Paisley, UK). ${ }^{45} \mathrm{CaCl}_{2}$ was obtained from by the National Centre for Nuclear Research, Radioisotope Centre POLATOM (Otwock, Poland). All the other chemicals were of analytical grade.

\section{Animals and Cell Culture}

Primary neuronal cultures were prepared from 7-day-old Wistar rats. For these experiments, we used rat pups, which were obtained from the animal colony of the Mossakowski Medical Research Centre, Polish Academy of Sciences in Warsaw. Mothers and pups were fed and watered ad libitum and kept on a 12:12 h dark-light cycle, at room temperature with a constant humidity of approximately $60 \%$. The procedures were approved by the Fourth Local Ethical Committee in Warsaw and were performed in accordance with EC Directive 86/609/EEC of 24 November 1986. We made all efforts to reduce the number of animals used and to minimize their suffering.

CGC were isolated and cultured according to a standard method (Schousboe et al. 1985), as described elsewhere (Zieminska et al. 2006a, 2012, 2014a, b). Briefly, the cerebella were chopped and trypsinized. Then, the cellular suspension obtained by trituration was centrifuged. The cells were re-suspended in Eagle's basal medium supplemented with $10 \%$ fetal calf serum, $25 \mathrm{mM} \mathrm{KCl}, 4 \mathrm{mM}$ glutamine, streptomycin $(50 \mu \mathrm{g} / \mathrm{ml})$, and penicillin $(50 \mathrm{U} / \mathrm{ml})$ and were seeded at a density of 1,2 or $4 \times 10^{6}$ cells per well on 24-,12- or 6-well plates (Thermo Scientific ${ }^{\mathrm{TM}} \mathrm{Nunc}^{\mathrm{TM}}$ ) coated with poly-L-lysine. After $48 \mathrm{~h}$ of culturing, $7.5 \mu \mathrm{M}$ cytosine arabinofuranoside was applied to inhibit DNA replication and the growth of non-neuronal cells. The experiments were performed after 7 days in vitro.

\section{Measurement of Changes in $\left[\mathrm{Ca}^{2+}\right]_{i}$}

Changes in intracellular $\mathrm{Ca}^{2+}$ concentration were measured using fluorometric methods exactly as described previously (Zieminska et al. 2014a, b). For the experiments using a confocal fluorescence microscope, the CGC cultures were loaded with the fluorescent calcium-sensitive probe fluo-3 via a 30-min incubation at $37{ }^{\circ} \mathrm{C}$ in the original growth medium containing $4 \mu \mathrm{M}$ fluo-3AM. Next, the growth medium was removed; the cells were washed three times with Locke 5 buffer containing $154 \mathrm{mM} \mathrm{NaCl}, 5 \mathrm{mM} \mathrm{KCl}$, $4 \mathrm{mM} \mathrm{NaHCO}, 2.3 \mathrm{mM} \mathrm{CaCl}_{2}, 5 \mathrm{mM}$ HEPES (pH 7.4), and $5 \mathrm{mM}$ glucose and pre-incubated for $5 \mathrm{~min}$ in this medium. Then, $0.5 \mu \mathrm{M}$ MK-801, and/or $2.5 \mu \mathrm{M}$ bastadin 12 together with $200 \mu \mathrm{M}$ ryanodine were added for an additional $5 \mathrm{~min}$ before application of TBBPA, DMSO, and positive controls glutamate or PCB 95, as presented in Figs. 1 and 5. The fluorescence of the cell-entrapped fluo-3 at $530 \mathrm{~nm}$ was measured every $30 \mathrm{~s}$ using an LSM 510 confocal microscope equipped with a 488-nm argon laser for the induction of fluorescence and the data acquisition software LSM 510 version 3.2 (Carl Zeiss AG, Jena, Germany). In experiments using a fluorescence plate reader (Fig. 2), CGC cultures $\left(1 \times 10^{6}\right.$ cells per well $)$ were preincubated with $4 \mu \mathrm{M}$ fluo-3AM. After washing the cultures three times with Locke 5 buffer, fluorescence was measured using a microplate reader (FLUOstar Omega, Germany) set at $485 \mathrm{~nm}$ excitation and $538 \mathrm{~nm}$ emission wavelengths. Baseline fluorescence was measured, and then the changes in fluorescence after the addition of each of the tested compounds were recorded every $60 \mathrm{~s}$.

There was no need to correct for autofluorescence in either of the two experimental settings, as it was stable and did not exceed $10 \%$ of the basal level of fluorescence of plates with fluo-3-loaded CGC. The results in Figs. 1 and 2 are presented graphically as percentages of the change in fluorescence in relation to the basal level $\left(\Delta F / F_{0} \%\right)$. In addition, quantitative data characterizing the increase in fluo-3 fluorescence above the basal level, measured just after the rapid phase of the $\mathrm{Ca}^{2+}$ transient and at the steady-state level, i.e., 60 and $300 \mathrm{~s}$ after TBBPA or glutamate application, respectively, and the significance of the differences are presented in Tables 1 and 2. The data in Fig. 1 and Table 1 were obtained in three independent experiments, each of which used a different preparation of CGC cultures. In each experiment, five wells were used per treatment. The results from each well consisted of the average data collected from 15 randomly selected objects: cell bodies or their conglomerates. Because the basal levels of fluorescence and the maximal responses to the positive control (100 $\mu \mathrm{M}$ glutamate) or to corresponding concentrations of TBBPA did not differ significantly among any of these experiments (one-way ANOVA, $p<0.05$ ), the corresponding data obtained in separate experiments were combined, analyzed as a single representative set for each treatment and presented as the mean \pm SD of 15 repetitions. The data in Fig. 2 and Table 2 (mean \pm SD) are the results of one example experiment, in which four wells were used for each treatment. This experiment was repeated three times, and qualitatively similar results were obtained. 

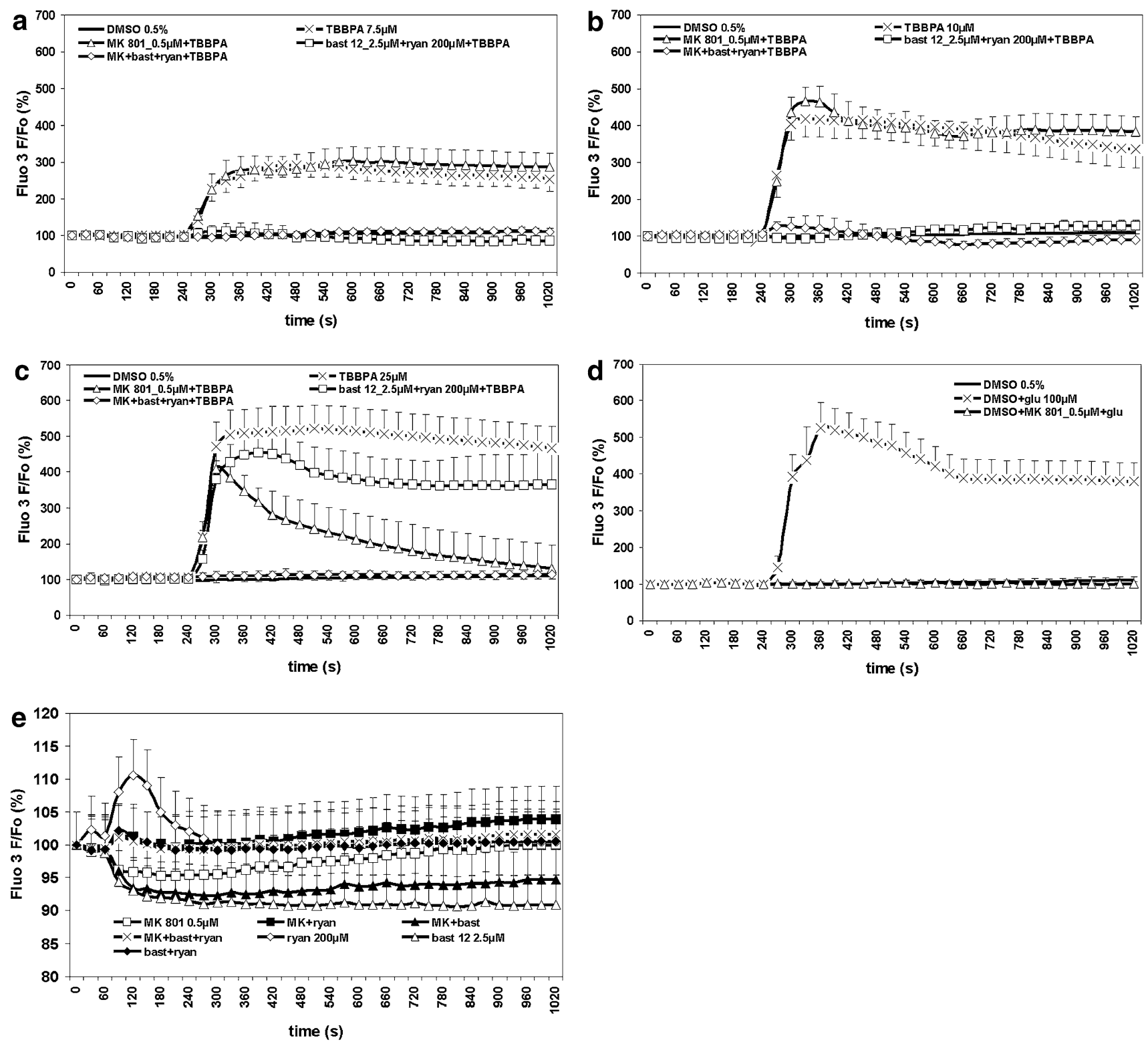

Fig. 1 TBBPA- and glutamate-induced changes in intracellular $\mathrm{Ca}^{2+}$ concentration in primary cultures of rat CGC measured with a confocal fluorescence microscope. The effects of TBBPA at concentrations of $7.5 \mu \mathrm{M}(\mathbf{a}), 10 \mu \mathrm{M}(\mathbf{b})$ and $25 \mu \mathrm{M}$ (c) or of $100 \mu \mathrm{M}$ glutamate (d) on the fluorescence of the fluo-3-loaded cells were measured in Locke 5 incubation medium containing, as indicated, vehicle (0.5\% DMSO),

\section{Measurement of ${ }^{45} \mathrm{Ca}$ Uptake}

The procedure was basically performed as described previously (Zieminska et al. 2014a). The CGC $\left(4 \times 10^{6} /\right.$ well $)$ were pre-incubated for $5 \mathrm{~min}$ in the Locke 5 medium, followed by a 5 -min incubation without or with $0.5 \mu \mathrm{M}$ MK-801 and/or $2.5 \mu \mathrm{M}$ bastadin 12 together with $200 \mu \mathrm{M}$ ryanodine. Then, $7.5,10$ or $25 \mu \mathrm{M}$ TBBPA, $0.5 \%$ DMSO (the vehicle control), or else the positive controls $100 \mu \mathrm{M}$ glutamate or $25 \mu \mathrm{M}$ PCB 95, were added for $10 \mathrm{~min}$

$0.5 \mu \mathrm{M}$ MK-801, and/or $2.5 \mu \mathrm{M}$ bastadin 12 (bast 12) with $200 \mu \mathrm{M}$ ryanodine (ryan). Panel (e) shows effects of MK-801, and bastadine 12 plus ryanodine applied without TBBPA. Fluo-3 fluorescence is expressed as a percentage of the basal level $\left(\Delta F / F_{0} \%\right)$. The results are the mean $\pm \mathrm{SD}(n=15)$. For the significance of differences among the experimental groups, see Table 1

together with ${ }^{45} \mathrm{CaCl}_{2}(1 \mu \mathrm{Ci} /$ well $)$. The incubation was terminated by washing with ice-cold calcium-free medium containing $2 \mathrm{mM}$ EGTA, and the cells were dissolved in $0.5 \mathrm{M} \mathrm{NaOH}$. The content of radioactive ${ }^{45} \mathrm{Ca}$ in the cultures was measured by liquid scintillation spectroscopy using a Wallac 1409 counter (Wallac, Turku, Finland). The data in Figs. 3 and 5 represent the mean \pm SD of 6 independent experiments using different CGC preparations. In each experiment, two wells were used per treatment, and the mean values were utilized for further calculations. 
Fig. 2 TBBPA-induced changes in intracellular $\mathrm{Ca}^{2+}$ concentration in primary cultures of rat CGC, as measured with a fluorescence plate reader. The effects of $7.5 \mu \mathrm{M}$ TBBPA on the fluorescence of the fluo-3loaded cultures were measured using pharmacological tools, as described for Fig. 1. Fluo-3 fluorescence is expressed as a percentage of the basal level $\left(\Delta F / F_{0} \%\right)$. The results are the mean $\pm \mathrm{SD}(n=4)$. For the significance of differences among the experimental groups, see Table 2

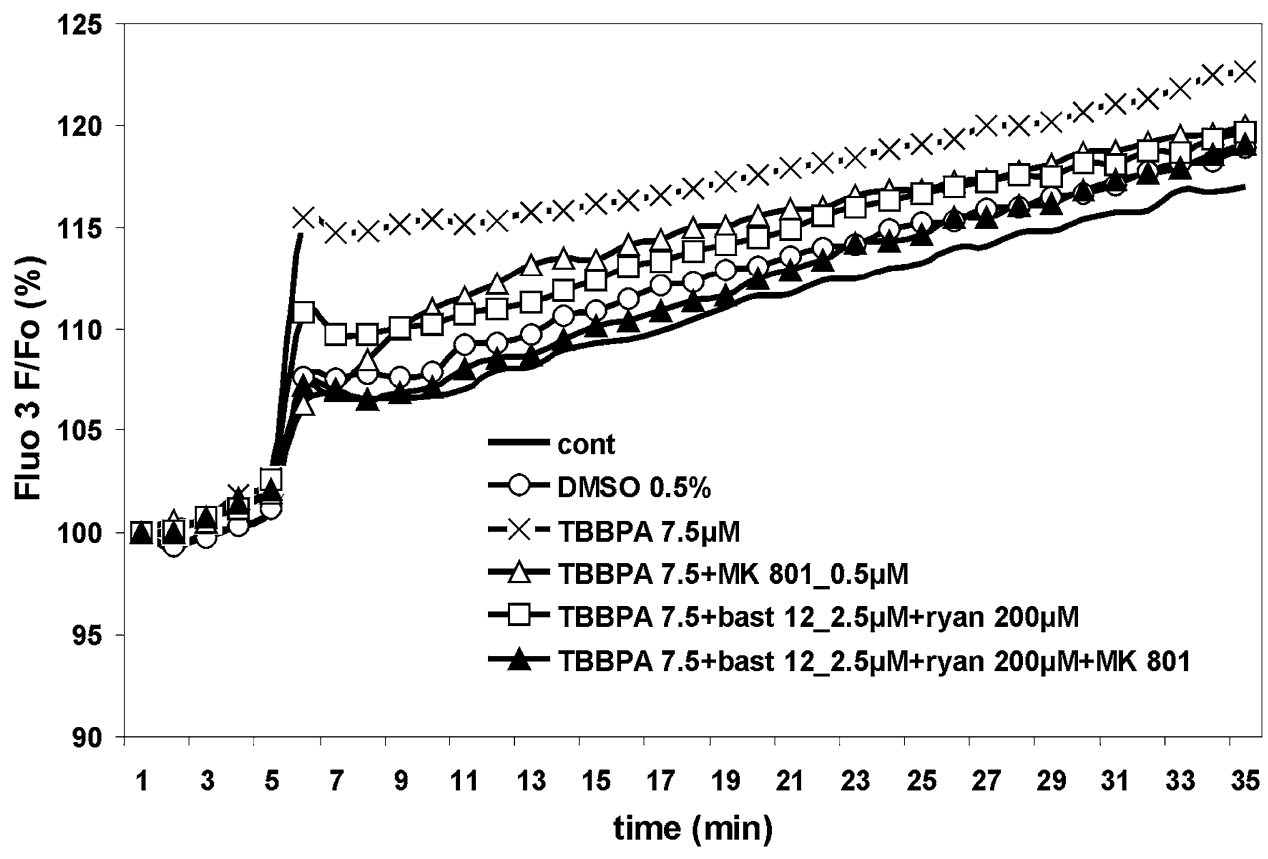

Table 1 Modulation by antagonists of NMDA and ryanodine receptors of TBBPA- and glutamate-evoked increases in intracellular Ca ${ }^{2+}$ concentration in primary cultures of rat cerebellar granule cells: fluorescence microscopy measurements

\begin{tabular}{|c|c|c|c|c|}
\hline \multirow[t]{2}{*}{ Treatment groups \& modulating substances $(\mu \mathrm{M})$} & TBBPA (7.5) & TBBPA (10) & TBBPA (25) & Glutamate (100) \\
\hline & \multicolumn{4}{|c|}{ Rise in fluo-3 fluorescence related to the baseline $(\%)$} \\
\hline \multicolumn{5}{|l|}{$60 \mathrm{~s}$ after TBBPA or glutamate application } \\
\hline None & $249 \pm 31^{\mathrm{a}}$ & $417 \pm 47^{\mathrm{a}}$ & $505 \pm 68^{\mathrm{a}}$ & $437 \pm 71^{\mathrm{a}}$ \\
\hline MK-801 (0.5) & $265 \pm 41^{\mathrm{a}}$ & $465 \pm 38^{\mathrm{a}}$ & $385 \pm 54^{\mathrm{a}}$ & $100 \pm 5^{\mathrm{a}}$ \\
\hline Bastadin $12(2.5)+$ ryanodine $(200)$ & $111 \pm 21^{\mathrm{b}}$ & $94 \pm 5^{\mathrm{b}}$ & $428 \pm 49^{\mathrm{a}, \mathrm{b}}$ & n.d. \\
\hline MK-801 + Bastadin 12 + ryanodine & $97 \pm 7^{\mathrm{b}}$ & $123 \pm 23^{\mathrm{b}}$ & $110 \pm 11^{\mathrm{b}}$ & n.d. \\
\hline \multicolumn{5}{|l|}{$300 s$ after TBBPA or glutamate application } \\
\hline None & $279 \pm 29^{\mathrm{a}}$ & $394 \pm 54^{\mathrm{a}}$ & $511 \pm 65^{\mathrm{a}}$ & $400 \pm 54^{\mathrm{a}}$ \\
\hline MK-801 (0.5) & $300 \pm 41^{\mathrm{a}}$ & $373 \pm 39^{\mathrm{a}}$ & $202 \pm 24^{\mathrm{a}, \mathrm{b}}$ & $102 \pm 5^{\mathrm{a}}$ \\
\hline Bastadin $12(2.5)+$ ryanodine $(200)$ & $92 \pm 15^{\mathrm{b}}$ & $118 \pm 7^{\mathrm{b}}$ & $373 \pm 59^{\mathrm{a}, \mathrm{b}}$ & n.d. \\
\hline MK-801 + Bastadin $12+$ ryanodine & $1107 \pm 7^{\mathrm{b}}$ & $80 \pm 12^{\mathrm{b}}$ & $114 \pm 11^{\mathrm{b}}$ & n.d. \\
\hline
\end{tabular}

The results of Fig. 1 characterizing the initial rises and steady-state levels of the fluo-3 fluorescence after the application of TBBPA or glutamate. Other information as described in legends to Fig. 1. Results are mean $\pm \mathrm{SD}(n=15)$

a Results significantly different from the baseline

${ }^{\mathrm{b}}$ Results significantly different from the corresponding groups untreated with modulating agents $(p<0.05)$

\section{Evaluation of CGC Viability}

The experiments were initiated by replacing the growth medium of the CGC cultures $\left(2 \times 10^{6}\right.$ cells per well $)$ with Locke 25 buffer containing $134 \mathrm{mM} \mathrm{NaCl}, 25 \mathrm{mM} \mathrm{KCl}$, $2.3 \mathrm{mM} \mathrm{CaCl}_{2}, 4 \mathrm{mM} \mathrm{NaHCO}, 5 \mathrm{mM}$ HEPES (pH 7.4), and $5 \mathrm{mM}$ glucose. As required, freshly prepared solutions of TBBPA or bastadin 12 (both in DMSO), vehicle (0.5\% DMSO), glutamate, or PCB 95 in DMSO (the positive controls), ryanodine, or MK-801 were also included. To evaluate TBBPA or glutamate toxicity, the cells were incubated with these substances at $37{ }^{\circ} \mathrm{C}$ for $30 \mathrm{~min}$; then, the exposure was terminated by two washes with Locke 25 buffer, and the CGC were cultured in the original growth medium for an additional $24 \mathrm{~h}$ under standard conditions (Ankarcrona et al. 1995, 1996). Finally, the cells were fixed with $80 \%$ methanol and stained with $0.5 \mu \mathrm{g} / \mathrm{ml}$ propidium iodide, and viable and dead neurons were counted using an Axiovert fluorescence microscope (Carl Zeiss AG, Germany) by an investigator who was blind to the experimental conditions, as described previously (Zieminska et al. 2006a). For visualization of changes in staining of 
Table 2 Modulation by antagonists of NMDA and ryanodine receptors of TBBPA-evoked increases in intracellular $\mathrm{Ca}^{2+}$ concentration in rat cerebellar granule cells in primary culture: fluorescence plate reader measurements

Treatment groups \& modulating substances $(\mu \mathrm{M})$

TBBPA (7.5) Rise in fluo-3 fluorescence related to the baseline $(\%)$

\begin{tabular}{ll}
\hline 60 s after TBBPA application & \\
None & $115 \pm 15^{\mathrm{a}}$ \\
MK-801 $(0.5)$ & $106 \pm 7$ \\
Bastadin $12(2.5)+$ ryanodine $(200)$ & $111 \pm 8$ \\
MK-801 + bastadin $12+$ ryanodine & $107 \pm 7^{\mathrm{b}}$ \\
300 s after TBBPA application & \\
None & $115 \pm 14^{\mathrm{a}}$ \\
MK-801 $(0.5)$ & $112 \pm 9^{\mathrm{a}}$ \\
Bastadin $12(2.5)+$ ryanodine $(200)$ & $111 \pm 9$ \\
MK-801 + bastadin $12+$ ryanodine & $109 \pm 8$
\end{tabular}

The results of Fig. 2 characterizing the initial rises and steady-state levels of the fluo-3 fluorescence after the application of TBBPA. Other information as described in legends to Fig. 2. Results are mean $\pm \mathrm{SD}(n=4)$, presenting data from one example experiment

${ }^{\text {a }}$ Results significantly different from the baseline

b Results significantly different from the corresponding groups untreated with modulating agents (one-way ANOVA test, $p<0.05$ )

nuclei with propidium iodide (Fig. 4a), we used a LSM 510 confocal microscope (Carl Zeiss AG, Germany) equipped with $546 \mathrm{~nm}$ HeNe laser for excitation, while pictures were taken at $617 \mathrm{~nm}$ emission wavelength. Neuronal viability was expressed as the percentage of live cells in proportion to all cells. For each experiment, the viability of the untreated cells was determined, and the data presented in Fig. 4 were normalized to these control values, which were set as $100 \%$. Moreover, the other cultures defined in Fig. 4 as the vehicle control were incubated for $30 \mathrm{~min}$ in Locke 25 buffer in the presence of $0.5 \%$ DMSO. In each experiment, two wells were used per treatment, and mean values were taken for calculations. The data represent the mean \pm SD of 6 independent experiments using different CGC preparations.

\section{Statistical Analysis}

The results are presented as mean \pm SD. Differences in corresponding data points between different groups were tested with one-way ANOVA followed by Dunn's correction method. For all tests, $p<0.05$ was considered significant. For the statistical analysis, Statistica software (ver. 10, StatSoft) was used.

\section{Results}

\section{TBBPA-Induced $\mathrm{Ca}^{2+}$ Imbalance in CGC}

Effects of TBBPA on $\left[\mathrm{Ca}^{2+}\right]_{i}$

Changes in fluo-3 fluorescence, which are indicative of the alterations in $\left[\mathrm{Ca}^{2+}\right]_{i}$, in the primary CGC cultures are presented in Figs. 1, 2 and 5, and in Tables 1 and 2
Fig. $3{ }^{45} \mathrm{Ca}$ uptake in primary cultures of rat CGC induced by $7.5,10$, and $25 \mu \mathrm{M}$ TBBPA or by $100 \mu \mathrm{M}$ glutamate. The cells were incubated in Locke 5 medium containing, as indicated, vehicle $(0.5 \%$ DMSO), $0.5 \mu \mathrm{M}$ MK-801, or $2.5 \mu \mathrm{M}$ bastadin 12 (bast 12) with $200 \mu \mathrm{M}$ ryanodine (ryan). The results are the mean \pm SD $(n=6)$. * The effects of TBBPA and glutamate are significantly different from the control groups. \# The effects of the inhibitors are significantly different from the corresponding TBBPA- or glutamate-treated groups $(p<0.05)$

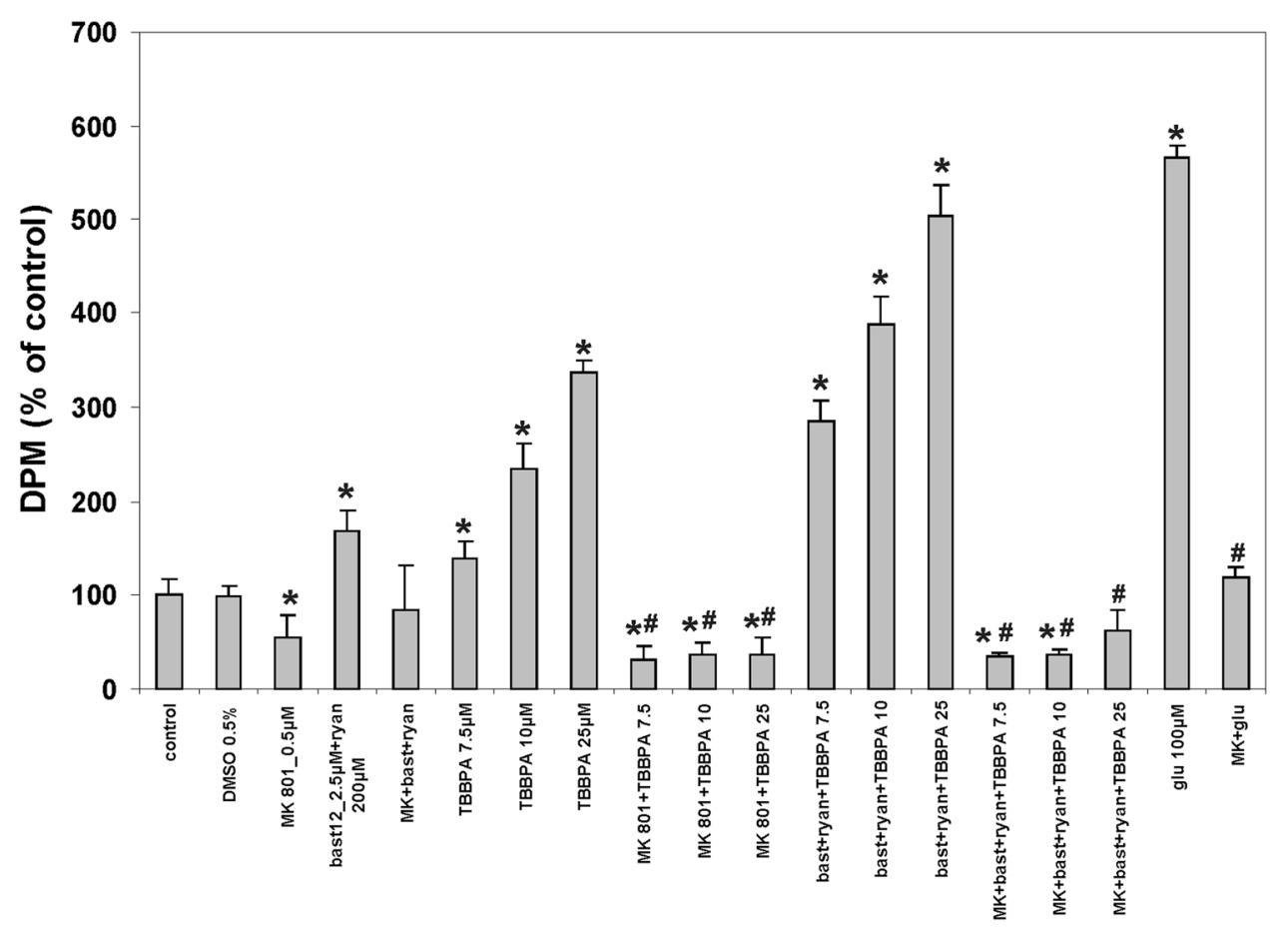



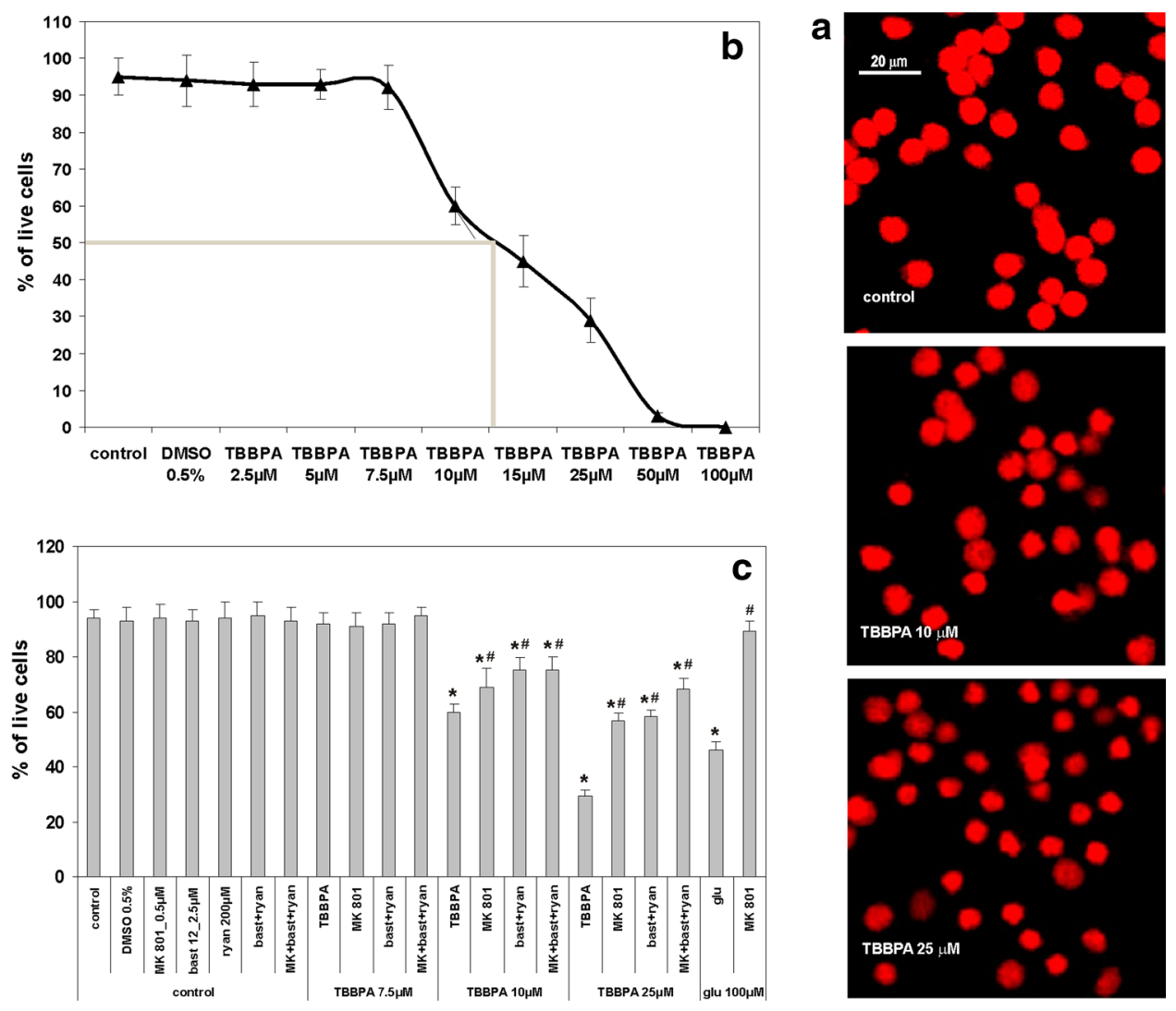

Fig. 4 Acute cytotoxicity induced by TBBPA in primary cultures of rat CGC. CGC, control or challenged with 10 and $20 \mu \mathrm{M}$ TBBPA, stained with propidium iodide (a). Evaluation of concentrationdependent acute cytotoxicity induced by TBBPA; the $\mathrm{LC}_{50}$ value for TBBPA equal to $12.5 \mu \mathrm{M}$ (b). Toxic effects of $7.5,10$, and $25 \mu \mathrm{M}$ TBBPA in comparison to that induced by $100 \mu \mathrm{M}$ glutamate in primary cultures of rat CGC: modulation by $0.5 \mu \mathrm{M}$ MK-801 and $2.5 \mu \mathrm{M}$ bastadin 12 plus $200 \mu \mathrm{M}$ ryanodine (c). The cells were incubated for $30 \mathrm{~min}$ in the ionic medium containing additions as

corresponding to Figs. 1 and 2. Measurements made with the confocal fluorescence microscope focused on the neuronal cell bodies and their conglomerates revealed that TBBPA applied at $7.5,10$, and $25 \mu \mathrm{M}$ concentrations induced a rapid, concentration-dependent increase in $\left[\mathrm{Ca}^{2+}\right]_{\mathrm{i}}$ to the maximal levels of 292,417 , and $521 \%$ relative to the basal level, respectively, whereas administration of the vehicle, $0.5 \%$ DMSO, did not change basal fluo-3 fluorescence (Fig. 1a-c; Table 1). The maximal increase in $\left[\mathrm{Ca}^{2+}\right]_{\mathrm{i}}$ evoked by $25 \mu \mathrm{M}$ TBBPA was similar in magnitude to the effects of both reference agents. Administration of $25 \mu \mathrm{M}$ PCB 95 resulted in $465 \%$ increase in $\left[\mathrm{Ca}^{2+}\right]_{\mathrm{i}}$ (Fig. 5), while $100 \mu \mathrm{M}$ glutamate produced a $526 \%$ increase in the intracellular $\mathrm{Ca}^{2+}$ level (Fig. 1d).

The NMDAR antagonist MK-801 $(0.5 \mu \mathrm{M})$, did not interfere with the increases in $\left[\mathrm{Ca}^{2+}\right]_{\mathrm{i}}$ induced by 7.5 and $10 \mu \mathrm{M}$ TBBPA (Fig. 1a, b) but partially reduced a similar effect evoked by $25 \mu \mathrm{M}$ TBBPA (Fig. 1c; Table 1). The indicated, and then were cultured in growth medium for $24 \mathrm{~h}$. The percentage of neurons surviving was determined by propidium iodide staining. The results are the mean $\pm \mathrm{SD}(n=6)$. * The effects of TBBPA are significantly different from the naïve control and DMSO (vehicle)-treated cells, and the effects of glutamate (glu) are significantly different from the control cells $(p<0.05)$. ${ }^{\#}$ The effects of MK-801 and bastadin 12 with ryanodine differ significantly from the effects of either TBBPA or glutamate alone $(p<0.05)$

increase in $\left[\mathrm{Ca}^{2+}\right]_{\mathrm{i}}$ induced by $100 \mu \mathrm{M}$ glutamate was completely inhibited by $0.5 \mu \mathrm{M}$ MK-801 (Fig. 1d). We also evaluated how $2.5 \mu \mathrm{M}$ bastadin 12 applied together with $200 \mu \mathrm{M}$ ryanodine, which were previously shown to inhibit the release of intracellular $\mathrm{Ca}^{2+}$ induced by $10 \mu \mathrm{M}$ TBBPA (Zieminska et al. 2014b), interferes with increases in $\left[\mathrm{Ca}^{2+}\right]_{\mathrm{i}}$ induced by TBBPA at the tested concentrations. The results of Fig. 1a, b demonstrated that the administration of bastadin 12 together with ryanodine completely inhibited the increases in $\left[\mathrm{Ca}^{2+}\right]_{\mathrm{i}}$ induced by 7.5 and $10 \mu \mathrm{M}$ TBBPA and that the additional application of $0.5 \mu \mathrm{M}$ MK-801 did not modify this effect (Fig. 1a, b). The increase in $\left[\mathrm{Ca}^{2+}\right]_{\mathrm{i}}$ evoked by $25 \mu \mathrm{M}$ TBBPA was partially reduced by bastadin 12 with ryanodine, whereas the combination of bastadin 12 and ryanodine with MK-801 completely abolished this effect (Fig. 1c; Table 1). As shown in Fig. 1e, application of MK-801, bastadine 12, and ryanodine alone or in combination, but in the absence of TBBPA, produced only minor changes in $\left[\mathrm{Ca}^{2+}\right]_{\mathrm{i}}$. In 


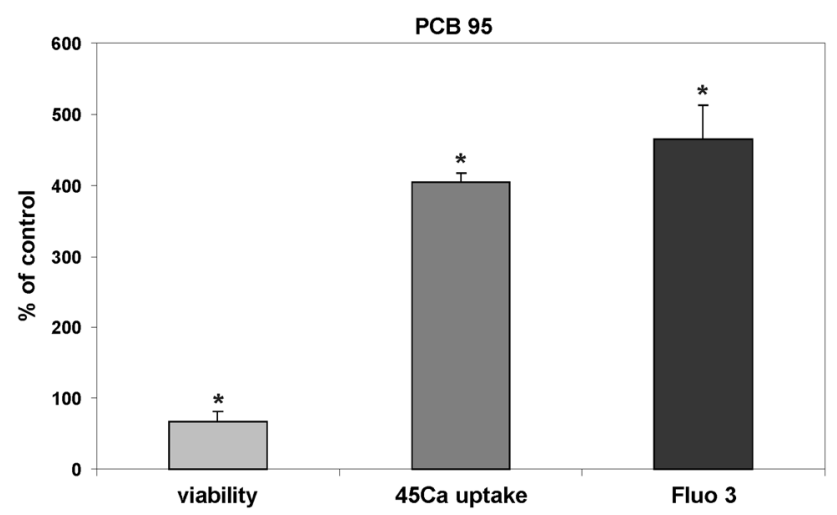

Fig. 5 The effect of $25 \mu \mathrm{M}$ PCB 95 on viability of primary cultures of rat CGC, intracellular $\mathrm{Ca}^{2+}$ level, and ${ }^{45} \mathrm{Ca}$ uptake. Further information as for Figs. 1, 3, and 4. * The effects of PCB 95 are significantly different from the corresponding control groups

particular, we detected a short-term and a slight increase in $\left[\mathrm{Ca}^{2+}\right]_{\mathrm{i}}$ after administration of ryanodine, a phenomenon already characterized in earlier studies (Hernández-Cruz et al. 1997; Zieminska et al. 2014b).

To verify the findings from the fluorescence microscope that MK-801 does not inhibit $\mathrm{Ca}^{2+}$ transients induced by TBBPA at low micromolar concentrations, in the next experiments, we examined changes in $\left[\mathrm{Ca}^{2+}\right]_{\mathrm{i}}$ evoked by $7.5 \mu \mathrm{M}$ TBBPA in CGC cultures using a fluorescence plate reader as a platform for measuring fluo-3 fluorescence. In contrast to the experiments using a fluorescence microscope, data from the fluorescence plate reader showed a steady upward trend of $\mathrm{F} / \mathrm{F}_{0} \%$ (Fig. 2), which is consistent with the observations of Heusinkveld and Westerink (2011) and Meijer et al. (2014). Control experiments showed no detectable effect of $2.5 \mu \mathrm{M}$ bastadin 12 or $200 \mu \mathrm{M}$ ryanodine applied alone on the basal level of $\left[\mathrm{Ca}^{2+}\right]_{i}$ (results not shown). Notwithstanding the slight increase in $\left[\mathrm{Ca}^{2+}\right]_{i}$ evoked by $7.5 \mu \mathrm{M}$ TBBPA, and a tendency to its partial inhibition by both MK-801 and bastadin 12 plus ryanodine, the application of these substances in combination resulted in a nearly complete inhibition of the $\mathrm{Ca}^{2+}$ transients (Fig. 2; Table 2). Qualitative data obtained in repetitive experiments, consistently demonstrated an inhibitory effect of MK-801 on the $\mathrm{Ca}^{2+}$ transients evoked by $7.5 \mu \mathrm{M}$ TBBPA. However, a large degree of variability in the $\mathrm{F} / \mathrm{F}_{0} \%$ level noted in individual experiments precluded reasonable presentation of the cumulative results of all of these experiments; therefore, only data from one example experiment are shown (Fig. 2; Table 2).

\section{Effects of TBBPA on ${ }^{45}$ Ca Uptake}

The results of measurements of ${ }^{45} \mathrm{Ca}$ uptake by CGC, which reflects the influx of extracellular $\mathrm{Ca}^{2+}$ into the neurons, are presented in Figs. 3 and 5 in relation to the level of ${ }^{45} \mathrm{Ca}$ that accumulated in untreated CGC (control). DMSO $(0.5 \%)$, the vehicle for TBBPA, bastadin 12 , and PCB 95, had no effect on ${ }^{45} \mathrm{Ca}$ uptake, whereas an antagonist of NMDARs, $0.5 \mu \mathrm{M}$ MK-801, reduced basal ${ }^{45} \mathrm{Ca}$ uptake by half (Fig. 3). This result reflects the level of ongoing glutamatergic neurotransmission mediated by NMDARs in CGC cultures. Application of the RyR antagonists, $2.5 \mu \mathrm{M}$ bastadin 12 together with $200 \mu \mathrm{M}$ ryanodine, potentiated ${ }^{45} \mathrm{Ca}$ uptake to $169 \%$ of the control, and this effect was completely abolished in the presence of MK-801 (Fig. 3). In the presence of $7.5 \mu \mathrm{M}$ TBBPA, the accumulation of radio-labeled $\mathrm{Ca}^{2+}$ by the CGC was $138 \%$ higher than the accumulation by the vehicle controltreated cells; it increased to $234 \%$ in the presence of $10 \mu \mathrm{M}$ TBBPA and to $336 \%$ by $25 \mu \mathrm{M}$ TBBPA. This concentration-dependent potentiation of ${ }^{45} \mathrm{Ca}$ uptake by TBBPA was completely inhibited by MK-801 but, in contrast, was increased in an additive manner by the RyR inhibitors, $2.5 \mu \mathrm{M}$ bastadin 12 with $200 \mu \mathrm{M}$ ryanodine. The latter effect was completely abolished by MK-801 (Fig. 3). Hundred $\mu \mathrm{M}$ glutamate, which served as positive control induced more than a five-fold rise in ${ }^{45} \mathrm{Ca}$ uptake, which was reduced to almost basal levels by MK- 801 (Fig. 3). Treatment with one other reference compound, $25 \mu \mathrm{M}$ PCB, has likewise increased ${ }^{45} \mathrm{Ca}$ uptake (a fourfold increase, Fig. 5).

\section{Effect of TBBPA on Cell Viability}

The results of Figs. 4 and 5 demonstrate the viability of the CGC $24 \mathrm{~h}$ after a $30 \mathrm{~min}$ incubation in the ionic medium. In control cultures that during such an incubation were not exposed to any pharmacological substances, viability was $94 \%$. Exposure of the neuronal cultures to $0.5 \%$ DMSO, which was the vehicle of TBBPA, bastadin 12 and PCB 95, had no additional effect on cell viability (Fig. 4b, c). The results of control experiments demonstrated that the exposure of CGC to ryanodine, bastadin 12 , or their combination without TBBPA did not influence neuronal viability (Fig. 4c). The same was true for the cells incubated with non-toxic $7.5 \mu \mathrm{M}$ TBBPA. Glutamate $(100 \mu \mathrm{M})$, which was applied as a positive control to induce the excitotoxicity that is mediated mainly by NMDARs, produced a pronounced, significant decrease in the percentage of live cells to $46 \%$. This toxic effect of glutamate was completely reversed in the presence of the NMDAR antagonist $0.5 \mu \mathrm{M}$ MK-801, which was nontoxic by itself when acutely applied (Fig. 4c). The other positive control PCB $95(25 \mu \mathrm{M})$ reduced viability of CGC to $67 \%$ (Fig. 5).

The data presented in Fig. 4a-c show that a $30 \mathrm{~min}$ exposure of CGC to $7.5 \mu \mathrm{M}$ TBBPA did not reduce the 
viability of the cells after $24 \mathrm{~h}$, whereas in cultures exposed to higher concentrations of TBBPA, significant cytotoxicity was found. Treatment with $10 \mu \mathrm{M}$ TBBPA reduced the percentage of live neurons to $60 \%$, while TBBPA at a concentration of $25 \mu \mathrm{M}$ led to a decrease of the percentage of live cells to only $29 \%$. TBBPA applied at 50 and $100 \mu \mathrm{M}$ concentration killed practically all the neuronal cells. The $\mathrm{LC}_{50}$ for TBBPA has been estimated to $12.5 \mu \mathrm{M}$ (Fig. 4b).

To assess the contribution of NMDARs and RyRs to TBBPA cytotoxicity, we applied $0.5 \mu \mathrm{M}$ MK-801 or $2.5 \mu \mathrm{M}$ bastadin 12 and $200 \mu \mathrm{M}$ ryanodine, respectively. As presented in Fig. 4c, MK-801 did not change the normal high viability of CGC incubated with $7.5 \mu \mathrm{M}$ TBBPA. MK-801 also slightly increased the percentage of live neurons after incubation with $10 \mu \mathrm{M}$ TBBPA, to $69 \%$. In CGC treated with $25 \mu \mathrm{M}$ TBBPA in the presence of $\mathrm{MK}-801$, the fraction of surviving neurons increased to $57 \%$. In turn the percentage of live CGC after incubation with $10 \mu \mathrm{M}$ TBBPA in the presence of ryanodine with bastadin 12 increased to approximately $75 \%$ and in the case of $25 \mu \mathrm{M}$ TBBPA, the percentage of live CGC increased to $58 \%$ (Fig. 4c). Thus, the application of MK-801 and bastadin 12 with ryanodine provided similar levels of cytoprotection. Moreover, as presented in Fig. 4c, the combination of the antagonists of NMDARs and RyRs had the same cytoprotective effect on CGC treated with $10 \mu \mathrm{M}$ TBBPA as these antagonists when applied separately. Only in the case of the cytotoxicity induced by $25 \mu \mathrm{M}$ TBBPA, the application of MK-801, bastadin 12, and ryanodine in combination increased the percentage of live neurons to approximately $68 \%$, and this level of viability was slightly but significantly $(p<0.05)$ higher than the viability observed after separate application of these antagonists of NMDARs and RyRs (Fig. 4c).

The above experiments revealed that a portion of TBBPA cytotoxicity was resistant to NMDAR and RyR inhibitors and therefore could be classified as independent of $\mathrm{Ca}^{2+}$ dyshomeostasis. We speculated that despite the removal of the TBBPA- and inhibitor-enriched ionic medium and extensive washing after the 30-min incubation a portion of the TBBPA could remain associated with the cells, in consequence destabilizing $\mathrm{Ca}^{2+}$ homeostasis during the additional $24 \mathrm{~h}$ of culturing. To account for this possibility, we performed complementary experiments in which CGC were cultured for $24 \mathrm{~h}$ in the presence of MK801 , bastadin 12 and ryanodine after completion of the exposure to TBBPA. The results of these experiments did not differ from the data presented in Fig. 4c, i.e., there was no enhancement of cytoprotection (results not shown), thus invalidating the caveat.

\section{Discussion}

In this study, we tested the roles of intracellular $\mathrm{Ca}^{2+}$ release via RyRs and of the influx of extracellular $\mathrm{Ca}^{2+}$ to neurons through NMDARs in TBBPA-evoked $\mathrm{Ca}^{2+}$ imbalance and cytotoxicity in primary cultures of rat CGC. The results demonstrated that the two mechanisms collectively contribute to the $\mathrm{Ca}^{2+}$ transients induced in neurons by TBBPA and subsequently participate in a considerable, but not overwhelming degree, to the cytotoxicity induced by acute challenge with TBBPA at concentrations $\geq 10 \mu \mathrm{M}$.

The primary culture of CGC is an in vitro model of glutamatergic neurons that has been widely used in neurobiological and neurotoxicological experiments (Schousboe et al. 1985; Contestabile 2002). We found this model particularly useful in mechanistic studies concerning the nature of $\mathrm{Ca}^{2+}$ transients in neurons and the mechanisms of the cytotoxicity of different compounds (Zieminska et al. 2006a, 2006-2007, 2010, 2012, 2014a, b). Importantly, CGC were utilized in the study of Reistad et al. (2007), which first demonstrated $\mathrm{Ca}^{2+}$ transients in neurons challenged with TBBPA at micromolar concentrations and showed that MK-801 protects these neuronal cultures against TBBPA-induced cytotoxicity. Later studies that used cell lines that do not express functional NMDARs drew attention to the TBBPA-induced release of intracellular $\mathrm{Ca}^{2+}$ via RyRs (Ogunbayo et al. 2008; Al-Mousa and Michelangeli 2012, 2014; Hendriks et al. 2014). Although our previous studies using CGC also showed TBBPA-induced intracellular $\mathrm{Ca}^{2+}$ release that seems to result from transformation of the functional RyRs into leak channels (Zieminska et al. 2012, 2014b), in the present work, we revisited the putative role of glutamate receptors in TBBPA-induced $\mathrm{Ca}^{2+}$ transients and cytotoxicity in neurons.

The basic pharmacological tool to verify the role of NMDARs in these experiments was their uncompetitive antagonist, MK-801. MK-801 was intentionally used at the relatively low concentration of $0.5 \mu \mathrm{M}$, which effectively inhibits NMDAR channels while avoiding off-target effects; for instance, MK-801 inhibits nicotinic acetylcholine receptor channels with an $\mathrm{IC}_{50}$ of as low as $3 \mu \mathrm{M}$ (Amador and Dani 1991). MK-801 is a high-affinity NMDAR channel blocker; studies of the cytoprotective effects of the enantiomers of MK-801, (+)MK-801, and $(-) \mathrm{MK}-801$, in $\mathrm{CGC}$ treated with $100 \mu \mathrm{M}$ glutamate demonstrated their $\mathrm{EC}_{50}$ to be $30 \mathrm{nM}$ and $150 \mathrm{nM}$, respectively (Lysko et al. 1992). Additionally, the present data (Figs. 1, 3) show that $0.5 \mu \mathrm{M}$ MK-801 almost completely inhibited glutamate-induced increases in $\left[\mathrm{Ca}^{2+}\right]_{\mathrm{i}}$ and ${ }^{45} \mathrm{Ca}$ influx in cultured CGC. 
Collective analysis of results of $\left[\mathrm{Ca}^{2+}\right]_{\mathrm{i}}$ measurements using a fluorescence microscope and a fluorescence plate reader, allows to conclude beyond doubt that NMDARs are involved in the TBBPA-evoked $\mathrm{Ca}^{2+}$ imbalance. While confocal fluorescence microscopy data bespeak concentration-dependent increases in $\left[\mathrm{Ca}^{2+}\right]_{\mathrm{i}}$ induced by $7.5,10$ and $25 \mu \mathrm{M}$ TBBPA, only the effect of TBBPA at the highest concentration was partially inhibited by MK-801 (Fig. 1). However, using a fluorescence plate reader, we showed that the partial MK-801-mediated inhibition of the increase in $\left[\mathrm{Ca}^{2+}\right]_{\mathrm{i}}$ was already evident for $7.5 \mu \mathrm{M}$ TBBPA (Fig. 2). In our previous studies, both confocal fluorescence microscopy and the fluorescence microplate readouts have proved useful for measuring changes in $\left[\mathrm{Ca}^{2+}\right]_{i}$ in CGC (Zieminska et al. 2006-2007, 2012, 2014a, b). We attribute the discrepancy of the current results to differences in the resolution of the measurements of fluo-3 fluorescence using the two different platforms. While the measurements using the fluorescence microscope were focused on neuronal cell bodies, which are rich in RyRcontaining endoplasmic reticulum but not in NMDA receptors, the fluorescence plate reader measures the mean intracellular $\mathrm{Ca}^{2+}$ changes in a population of CGC (Berman and Murray 2000), including dendrite-rich regions with a high density of NMDARs.

Our results confirm the recently published data of Meijer et al. (2014), who showed quantitative and qualitative differences between the results obtained using a fluorescence microscope and a fluorescence plate reader. Meijer et al. (2014) claimed that due to its higher sensitivity and reliability, single-cell fluorescence microscopy is superior to plate reader methods as a tool to assess in vitro neurotoxicity basing on intracellular $\mathrm{Ca}^{2+}$ recording. In our study, despite certain obvious limitations, the plate reader method, provided valid data. Of particular importance is that the results of our plate reader-based measurement of $7.5 \mu \mathrm{M}$ TBBPA-evoked increases in intracellular $\mathrm{Ca}^{2+}$ levels and their sensitivity to MK-801 inhibition (Fig. 2; Table 2) were fully compatible with the results of measurements of ${ }^{45} \mathrm{Ca}$ uptake in the presence of TBBPA at the same concentration (Fig. 3, see "Discussion" section below).

The measurements of ${ }^{45} \mathrm{Ca}$ uptake in CGC conclusively demonstrated the participation of NMDARs in the $\mathrm{Ca}^{2+}$ imbalance caused by TBBPA-induced neuronal $\mathrm{Ca}^{2+}$ influx. TBBPA $(7.5,10$, and $25 \mu \mathrm{M})$ concentration-dependently increased ${ }^{45} \mathrm{Ca}$ uptake, which was completely abolished by MK-801. Treatment with the RyR-inhibiting mixture composed of bastadin 12 with ryanodine did not reduce this effect, but instead produced MK-801-sensitive increases in ${ }^{45} \mathrm{Ca}$ uptake (Fig. 3). The effect induced by bastadin 12 plus ryanodine seems to result from short-term activation by ryanodine of the RyR channels, leading to transient increase in $\left[\mathrm{Ca}^{2+}\right]_{i}$ (Fig. 1e). Such increase may trigger glutamate release from the neurotransmitter pool in the presynaptic terminals leading to activation of the NMDARs and MK-801-sensitive calcium entry to neurons. Stimulatory effects of TBBPA and of bastadin 12 plus ryanodine on ${ }^{45} \mathrm{Ca}$ uptake in $\mathrm{CGC}$ were additive, suggesting that they reflect different mechanisms. The short-lived intracellular $\mathrm{Ca}^{2+}$ release via RyRs induced by ryanodine is unlikely to reflect neuroprotective properties attributed to upregulation of RyRs in neurons under different experimental conditions (Supnet et al. 2010).

Although the mechanism of the latter phenomenon is not well understood, it is unlikely to have anything to do with the effects of TBBPA. The main results of the ${ }^{45} \mathrm{Ca}$ uptake measurements collectively indicate that in CGC, the administration of TBBPA leads to the activation of NMDARs, which is independent of TBBPA-evoked intracellular $\mathrm{Ca}^{2+}$ release. The results also indicate that the influx of extracellular $\mathrm{Ca}^{2+}$ into TBBPA-treated neurons is mediated exclusively by NMDARs. The latter finding is consistent with the data of Hendriks et al. (2012), who indicated that TBBPA inhibits voltage-gated calcium channels. Also one of the positive control PCB 95 potently increases ${ }^{45} \mathrm{Ca}$ uptake in CGC (Fig. 5), which is consistent with the observation that this substance not only induces intracellular $\mathrm{Ca}^{2+}$ release via RyRs, but also amplifies ionotropic glutamate receptor signaling (Gafni et al. 2004).

The mechanism underlying the TBBPA-induced activation of NMDARs in CGC is unclear and may be complex. Reistad et al. (2007) attributed the TBBPA-evoked increase in $\left[\mathrm{Ca}^{2+}\right]_{i}$ to the accumulation of glutamate and aspartate in the incubation medium, resulting from the previously described TBBPA-mediated inhibition of glutamate transporters in neuronal plasma membranes (Mariussen and Fonnum 2003). However, these authors observed such an increase in glutamate level after incubating the CGC with TBBPA for at least 90 min (Reistad et al. 2007), while TBBPA-induced increases in $\left[\mathrm{Ca}^{2+}\right]_{\mathrm{i}}$ and ${ }^{45} \mathrm{Ca}$ uptake are immediate (Figs. 1, 2, 3). The glutamate that potentially activates NMDARs in neurons treated with TBBPA could also be released from presynaptic nerve terminals, which could be triggered by the release of intracellular $\mathrm{Ca}^{2+}$ via RyRs (for review see Nizami et al. 2010). However, in the present study, the TBBPA-evoked increase in ${ }^{45} \mathrm{Ca}$ uptake was not inhibited by bastadin 12 with ryanodine (Fig. 3), which does not support such an explanation. Rather, this result indicates that the activation of NMDARs in CGC treated with TBBPA is independent of intracellular $\mathrm{Ca}^{2+}$ release.

The increase of $\left[\mathrm{Ca}^{2+}\right]_{\mathrm{i}}$ in cell cultures treated with TBBPA have been shown in several studies using various models (Reistad et al. 2007; Ogunbayo et al. 2008; AlMousa and Michelangeli 2012, 2014; Hendriks et al. 2014; 
Zieminska et al. 2014b). The role of RyRs in this phenomenon has been previously demonstrated (Ogunbayo et al. 2008; Zieminska et al. 2014b). Our present results add credence to the previous observations by demonstrating that bastadin 12 plus ryanodine inhibited increases in $\left[\mathrm{Ca}^{2+}\right]_{\mathrm{i}}$ evoked by TBBPA (Figs. 1, 2). As such, combination of the two drugs turned out to provide a pharmacological tool to determine the relative contribution of RyR-mediated intracellular $\mathrm{Ca}^{2+}$ release in TBBPAevoked cytotoxicity in neurons.

We noticed that irrespective of TBBPA concentration and the platform used for $\mathrm{Ca}^{2+}$ measurements, simultaneous application of inhibitors of NMDAR-mediated neuronal $\mathrm{Ca}^{2+}$ influx and of RyR-mediated $\mathrm{Ca}^{2+}$ release completely abolished the increases in $\left[\mathrm{Ca}^{2+}\right]_{\mathrm{i}}$ evoked by TBBPA. These results indicate that NMDARs and RyRs are the only $\mathrm{Ca}^{2+}$ ionophores involved in TBBPA-induced $\mathrm{Ca}^{2+}$ transients in CGC. This finding is consistent with the data of Hendriks et al. (2012), who suggested that TBBPA strongly inhibits the activity of voltage-gated $\mathrm{Ca}^{2+}$ channels. Similarities of the effects of TBBPA, thapsigargin, and PCB95 on intracellular $\mathrm{Ca}^{2+}$ stores have been previously demonstrated (Mack et al. 1994; Gafni et al. 2004; Pessah et al. 2010; Zieminska et al. 2014b). Our present data clearly bespeak a similar potential of TBBPA and PCB 95 in inducing $\mathrm{Ca}^{2+}$ transients in CGC, suggesting similar underlying mechanisms, in either case comprising the transformation of RyRs into leak channels.

Collectively, our calcium studies showed that, even at low $\mu \mathrm{M}$ concentrations, TBBPA activates NMDARs and RyRs, and the activation of both of these channels participates in the increase in $\left[\mathrm{Ca}^{2+}\right]_{i}$ in CGC. It may be tempting to speculate that the effects are positively looped: $\mathrm{Ca}^{2+}$ influx into neurons via the activation of NMDARs could potentiate the mobilization of $\mathrm{Ca}^{2+}$ from ryanodinesensitive intracellular stores via calcium-induced calcium release, while the increase of $\left[\mathrm{Ca}^{2+}\right]_{i}$ could trigger glutamate secretion from presynaptic nerve terminals, activating NMDARs. In so far, the present results failed to provide support to the concept, rather suggesting that the TBBPAmediated activation of NMDARs and RyRs in CGC are two independent processes.

After identifying the mechanisms of TBBPA-induced $\mathrm{Ca}^{2+}$ imbalance in primary CGC cultures, we evaluated their role in the cytotoxicity of TBBPA. In the present experiments, CGC were acutely challenged with TBBPA for the measurements of both $\mathrm{Ca}^{2+}$ transients and cytotoxicity, the latter being assessed with a 24-h delay. Moreover, in the present experiments, the exposure of the CGC to TBBPA was performed exclusively using serumfree incubation medium because of the high hydrophobicity of TBBPA and the ease with which it binds to proteins. Our experience is that prolonged incubation or culturing of
CGC under serum-free conditions is poorly tolerated by these cells. The present experimental protocol differs from that of several other studies addressing the mechanisms of TBBPA cytotoxicity, which usually examined the survival of the cells after a prolonged 18 or $24 \mathrm{~h}$ incubation with TBBPA, whereas TBBPA-evoked changes in intracellular $\mathrm{Ca}^{2+}$ levels were measured during acute exposure to this substance (Al-Mousa and Michelangeli 2012; Hendriks et al. 2012, 2014; Ogunbayo et al. 2008; Reistad et al. 2007). It is worth noting that the $\mathrm{LC}_{50}$ value of $12.5 \mu \mathrm{M}$ found for TBBPA in our study (Fig. 1a) is very close to values of $7-15 \mu \mathrm{M}$ which have been published by others (Al-Mousa and Michelangeli 2012; Reistad et al. 2007). Whether and in what degree the present protocol is congruent with the status anticipated in the in vivo setting remains to be seen.

In our experiments, staining with propidium iodide was used to evaluate the percentage of dead cells (Ankarcrona et al. 1995). Although the authors of this method originally designed it to visualize apoptosis (Ankarcrona et al. 1996), in the present study, we did not differentiate between necrotic and apoptotic neuronal death because this distinction was not the purpose of the present study. There are divergent opinions concerning TBBPA-induced apoptosis in neurons. While Reistad et al. (2007) suggested that TBBPA induces caspase-independent apoptosis in CGC, Wojtowicz et al. (2014) described TBBPA-induced caspase-3-dependent apoptosis of primary cortical cells, followed by secondary necrosis.

Our results (Fig. 4a, b) showed that an acute, 30-min exposure of CGC to $7.5 \mu \mathrm{M}$ TBBPA was below the threshold of cytotoxicity, although it resulted in both ${ }^{45} \mathrm{Ca}$ uptake and an increase in $\left[\mathrm{Ca}^{2+}\right]_{\mathrm{i}}$. At 10 and $25 \mu \mathrm{M}$ concentrations, TBBPA-induced concentration-dependent cytotoxicity, which was equally and only partially reduced by the separate application of MK-801 or bastadin 12 with ryanodine. It is noteworthy that combined application of all of these inhibitors, which completely abolished TBBPAevoked increases in $\left[\mathrm{Ca}^{2+}\right]_{\mathrm{i}}$, only slightly increased cytoprotection. There was also a lack of an additional increase in the rate of cytoprotection when all of these inhibitors were present during the entire 24-h CGC culturing period after the TBBPA challenge (results not shown). These data indicate that the mechanisms that trigger TBBPA cytotoxicity in $\mathrm{CGC}$ are complex, comprising both $\mathrm{Ca}^{2+}$-dependent, NMDAR- and RyR- mediated processes and $\mathrm{Ca}^{2+}$-independent processes.

As has been previously demonstrated by Reistad et al. (2007), MK-801 at a concentration of $3 \mu \mathrm{M}$ provided very effective cytoprotection of the CGC incubated for $24 \mathrm{~h}$ in the presence of $10 \mu \mathrm{M}$ TBBPA; incubating the cultures in $\mathrm{Ca}^{2+}$-free buffer provided less extensive protection from this cytotoxicity, suggesting a role of $\mathrm{Ca}^{2+}$ influx via 
NMDARs in TBBPA cytotoxicity. Our present results, which were obtained under different conditions involving the acute exposure of CGC to TBBPA and using $0.5 \mu \mathrm{M}$ MK-801, together with new data on $\mathrm{Ca}^{2+}$ transients, directly confirmed the role of NMDARs in TBBPA cytotoxicity. Moreover, we confirmed the cytoprotective potential of the well-tolerated RyR-inhibiting mixture composed of bastadin 12 with ryanodine. Although the efficacy of these substances in the inhibition of intracellular $\mathrm{Ca}^{2+}$ release in CGC challenged with thapsigargin or TBBPA was demonstrated previously (Zieminska et al. 2006-2007, 2014b), to our knowledge, this is the first use of bastadin 12 and ryanodine in the study of the cytotoxicity of $\mathrm{Ca}^{2+}$ releasers in neurons. New results include the observation that the inhibition of TBBPA-induced intracellular $\mathrm{Ca}^{2+}$ release was as effective as the NMDAR antagonist MK-801 in providing neuroprotection and that, in addition to the $\mathrm{Ca}^{2+}$-dependent mechanisms of TBBPA cytotoxicity, there are mechanisms not directly related to increases in intracellular $\mathrm{Ca}^{2+}$.

When focusing attention on $\mathrm{Ca}^{2+}$ imbalance, one should remember that oxidative stress and enhanced ROS production reportedly contribute to the mechanisms of TBBPA cytotoxicity in different experimental models, including CGC (Szymanska et al. 2000; Shi et al. 2005; Reistad et al. 2007; Zieminska et al. 2012). We tentatively propose that the putative $\mathrm{Ca}^{2+}$-independent production of ROS may be involved in the toxic effects of TBBPA in CGC that are resistant to the protection extended by MK801 and bastadin 12 with ryanodine.

TBBPA is a putative environmental pollutant that is also present in biological samples (Alaee and Wenning 2002; de Wit 2002). Different BFRs and PCBs affect $\mathrm{Ca}^{2+}$ homeostasis and intracellular signaling in neurons (Kodavanti et al. 2005; Pessah et al. 2010; Reistad et al. 2007; Ogunbayo et al. 2008, Hendriks et al. 2012). Our present results provide new information on the role of NMDARs and RyRs in the mechanisms of $\mathrm{Ca}^{2+}$ imbalance and cytotoxicity in neurons that have been acutely exposed to TBBPA at micromolar concentrations. Hendriks et al. (2012) demonstrated that nicotinic acetylcholine and GABA receptors and voltage-gated calcium channels are also targets of TBBPA interactions. These data are worrying. However, caution is needed when extrapolating these in vitro results to an in vivo situation. TBBPA concentrations in human plasma do not exceed low nanomolar levels (Reistad et al. 2007), and acute poisoning with higher TBBPA doses in industry seems highly unlikely (Szymanska et al. 2000). Moreover, based on the short half-life and lack of biomagnification in the food web, TBBPA can be considered a weak environmental toxin (Darnerud 2003; Sjödin et al. 2003). However, TBBPA is an intriguing pleiotropic toxin, and studies of the mechanisms of its interference may disclose new relations between signaling pathways in neurons.

In conclusion, the results of this in vitro study directly demonstrated that in CGC, TBBPA-induced increases in $\left[\mathrm{Ca}^{2+}\right]_{\mathrm{i}}$ are due to the influx of $\mathrm{Ca}^{2+}$ ions into neurons via NMDARs and their release from intracellular stores through leaky RyRs; both of these processes, as well as other $\mathrm{Ca}^{2+}$-independent mechanism(s), are involved in the acute cytotoxicity of TBBPA.

Acknowledgments The authors are grateful to Professor Elias Couladouros and Dr. Emmanuel Pitsinos (NCSR "Demokritos," Athens, Greece) for supplying synthetic bastadin 12 and to American Journal Experts for English language editing. This study was supported by the Polish National Science Centre Grant No. 2012/05/B/ NZ7/03225.

\section{Compliance with Ethical Standards}

Conflict of interest The authors declare no competing interest.

Open Access This article is distributed under the terms of the Creative Commons Attribution 4.0 International License (http://crea tivecommons.org/licenses/by/4.0/), which permits unrestricted use, distribution, and reproduction in any medium, provided you give appropriate credit to the original author(s) and the source, provide a link to the Creative Commons license, and indicate if changes were made.

\section{References}

Alaee M, Wenning RJ (2002) The significance of brominated flame retardants in the environment: current understanding, issues and challenges. Chemosphere 46:579-582

Al-Mousa F, Michelangeli F (2012) Some commonly used brominated flame retardants cause $\mathrm{Ca}^{2+}$-ATPase inhibition, betaamyloid peptide release and apoptosis in SH-SY5Y neuronal cells. PLoS One 7:e33059

Al-Mousa F, Michelangeli F (2014) The sarcoplasmic-endoplasmic reticulum $\mathrm{Ca}^{2+}$-ATPase (SERCA) is the likely molecular target for the acute toxicity of the brominated flame retardant hexabromocyclododecane (HBCD). Chem Biol Interact 207:1-6

Altamirano F, López JR, Henríquez C, Molinski T, Allen PD, Jaimovich E (2012) Increased resting intracellular calcium modulates NF- $\kappa \mathrm{B}$-dependent inducible nitric-oxide synthase gene expression in dystrophic $\mathrm{mdx}$ skeletal myotubes. J Biol Chem 287:20876-20887

Amador M, Dani JA (1991) MK-801 inhibition of nicotinic acetylcholine receptor channels. Synapse 7:207-215

Ankarcrona M, Dypbukt JM, Bonfoco E, Zhivotovsky B, Orrenius S, Lipton SA, Nicotera P (1995) Glutamate-induced neuronal death: a succession of necrosis or apoptosis depending on mitochondrial function. Neuron 15:961-973

Ankarcrona M, Dypbukt JM, Orrenius S, Nicotera P (1996) Calcineurin and mitochondrial function in glutamate-induced neuronal cell death. FEBS Lett 394:321-324

Berman FW, Murray TF (2000) Brevetoxin-induced autocrine excitotoxicity is associated with manifold routes of $\mathrm{Ca}^{2+}$ influx. J Neurochem 74:1443-1451

Canesi L, Lorusso LC, Ciacci C, Betti M, Gallo G (2005) Effects of the brominated flame retardant tetrabromobisphenol-A (TBBPA) 
on cell signaling and function of Mytilus hemocytes: involvement of MAP kinases and protein kinase C. Aquat Toxicol 75:277-287

Chen L, Molinski TF, Pessah IN (1999) Bastadin 10 stabilizes the open conformation of the ryanodine-sensitive $\mathrm{Ca}^{2+}$ channel in an FKBP12-dependent manner. J Biol Chem 274:32603-32612

Choi DW (1985) Glutamate neurotoxicity in cortical cell culture is calcium dependent. Neurosci Lett 58:293-297

Contestabile A (2002) Cerebellar granule cells as a model to study mechanisms of neuronal apoptosis or survival in vivo and in vitro. Cerebellum 1:41-55

Couladouros EA, Pitsinos EN, Moutsos VI, Sarakinos G (2005) A general method for the synthesis of bastaranes and isobastaranes: first total synthesis of bastadins 5, 10, 12, 16, 20, and 21 . Chemistry 11:406-421

Darnerud PO (2003) Toxic effects of brominated flame retardants in man and in wildlife. Environ Int 29:841-853

de Wit CA (2002) An overview of brominated flame retardants in the environment. Chemosphere 46:583-624

Eltit JM, Yang T, Li H, Molinski TF, Pessah IN, Allen PD, Lopez JR (2010) RyR1-mediated $\mathrm{Ca}^{2+}$ leak and $\mathrm{Ca}^{2+}$ entry determine resting intracellular $\mathrm{Ca}^{2+}$ in skeletal myotubes. J Biol Chem 285:13781-13787

Fill M, Copello JA (2002) Ryanodine receptor calcium release channels. Physiol Rev 82:893-922

Gafni J, Wong PW, Pessah IN (2004) Non-coplanar 2,2',3,5',6pentachlorobiphenyl (PCB 95) amplifies ionotropic glutamate receptor signaling in embryonic cerebellar granule neurons by a mechanism involving ryanodine receptors. Toxicol Sci 77:72-82

Hendriks HS, van Kleef RG, van den Berg M, Westerink RH (2012) Multiple novel modes of action involved in the in vitro neurotoxic effects of tetrabromobisphenol-A. Toxicol Sci 128:235-246

Hendriks HS, Meijer M, Muilwijk M, van den Berg M, Westerink RH (2014) A comparison of the in vitro cyto- and neurotoxicity of brominated and halogen-free flame retardants: prioritization in search for safe(r) alternatives. Arch Toxicol 88:857-869

Hernández-Cruz A, Escobar AL, Jiménez N (1997) $\mathrm{Ca}^{2+}$-induced $\mathrm{Ca}^{2+}$ release phenomena in mammalian sympathetic neurons are critically dependent on the rate of rise of trigger $\mathrm{Ca}^{2+}$. J Gen Physiol 109:147-167

Heusinkveld HJ, Westerink RH (2011) Caveats and limitations of plate reader-based high-throughput kinetic measurements of intracellular calcium levels. Toxicol Appl Pharmacol 255:1-8

Kitamura S, Suzuki T, Sanoh S, Kohta R, Jinno N, Sugihara K, Yoshihara S, Fujimoto N, Watanabe H, Ohta S (2005) Comparative study of the endocrine-disrupting activity of bisphenol A and 19 related compounds. Toxicol Sci 84:249-259

Kodavanti PR, Ward TR, Ludewig G, Robertson LW, Birnbaum LS (2005) Polybrominated diphenyl ether (PBDE) effects in rat neuronal cultures: 14C-PBDE accumulation, biological effects, and structure-activity relationships. Toxicol Sci 88:181-192

Lysko PG, Gagnon RC, Yue TL, Gu JL, Feuerstein G (1992) Neuroprotective effects of SKF 10,047 in cultured rat cerebellar neurons and in gerbil global brain ischemia. Stroke 23:414-419

Mack MM, Molinski TF, Buck ED, Pessah IN (1994) Novel modulators of skeletal muscle FKBP12/calcium channel complex from Ianthella basta. Role of FKBP12 in channel gating. J Biol Chem 269:23236-23249

Mariussen E, Fonnum F (2003) The effect of brominated flame retardants on neurotransmitter uptake into rat brain synaptosomes and vesicles. Neurochem Int 43:533-542

Meijer M, Hendriks HS, Heusinkveld HJ, Langeveld WT, Westerink RH (2014) Comparison of plate reader-based methods with fluorescence microscopy for measurements of intracellular calcium levels for the assessment of in vitro neurotoxicity. Neurotoxicology 45C:31-37

Nakajima A, Saigusa D, Tetsu N, Yamakuni T, Tomioka Y, Hishinuma T (2009) Neurobehavioral effects of tetrabromobisphenol A, a brominated flame retardant, in mice. Toxicol Lett 189:78-83

Nizami S, Lee VW, Davies J, Long P, Jovanovic JN, Sihra TS (2010) Presynaptic roles of intracellular $\mathrm{Ca}^{2+}$ stores in signaling and exocytosis. Biochem Soc Trans 38:529-535

Ogunbayo OA, Michelangeli F (2007) The widely utilized brominated flame retardant tetrabromobisphenol A (TBBPA) is a potent inhibitor of the SERCA $\mathrm{Ca}^{2+}$ pump. Biochem $\mathrm{J}$ 408:407-415

Ogunbayo OA, Lai PF, Connolly TJ, Michelangeli F (2008) Tetrabromobisphenol A (TBBPA), induces cell death in TM4 Sertoli cells by modulating $\mathrm{Ca}^{2+}$ transport proteins and causing dysregulation of $\mathrm{Ca}^{2+}$ homeostasis. Toxicol Vitro 22:943-952

Pessah IN, Molinski TF, Meloy TD, Wong P, Buck ED, Allen PD, Mohr FC, Mack MM (1997) Bastadins relate ryanodine-sensitive and -insensitive $\mathrm{Ca}^{2+}$ efflux pathways in skeletal SR and $\mathrm{BC} 3 \mathrm{H} 1$ cells. Am J Physiol 272:C601-C614

Pessah IN, Cherednichenko G, Lein PJ (2010) Minding the calcium store: ryanodine receptor activation as a convergent mechanism of PCB toxicity. Pharmacol Ther 125:260-285

Reistad T, Mariussen E, Fonnum F (2005) The effect of a brominated flame retardant, tetrabromobisphenol-A, on free radical formation in human neutrophil granulocytes: the involvement of the MAP kinase pathway and protein kinase C. Toxicol Sci 83:89-100

Reistad T, Mariussen E, Ring A, Fonnum F (2007) In vitro toxicity of tetrabromobisphenol-A on cerebellar granule cells: cell death, free radical formation, calcium influx and extracellular glutamate. Toxicol Sci 96:268-278

Schousboe A, Drejer J, Hansen GH, Meier E (1985) Cultured neurons as model systems for biochemical and pharmacological studies on receptors for neurotransmitter amino acids. Dev Neurosci $7: 252-262$

Shi H, Wang X, Luo Y, Su Y (2005) Electron paramagnetic resonance evidence of hydroxyl radical generation and oxidative damage induced by tetrabromobisphenol A in Carassius auratus. Aquat Toxicol 74:365-371

Silverstein FS, Nelson C (1992) The microsomal calcium-ATPase inhibitor thapsigargin is a neurotoxin in perinatal rodent brain. Neurosci Lett 145:157-160

Sjödin A, Patterson DG Jr, Bergman A (2003) A review on human exposure to brominated flame retardants-particularly polybrominated diphenyl ethers. Environ Int 29:829-839

Stirling DP, Cummins K, Wayne Chen SR, Stys P (2014) Axoplasmic reticulum $\mathrm{Ca}^{2+}$ release causes secondary degeneration of spinal axons. Ann Neurol 75:220-229

Supnet C, Noonan C, Richard K, Bradley K, Mayne M (2010) Upregulation of the type 3 ryanodine receptor is neuroprotective in the TgCRND8 mouse model of Alzheimer's disease. J Neurochem 112:356-365

Szydlowska K, Tymianski M (2010) Calcium, ischemia and excitotoxicity. Cell Calcium 47:122-129

Szymanska JA, Piotrowski JK, Frydrych B (2000) Hepatotoxicity of tetrabromobisphenol-A: effects of repeated dosage in rats. Toxicology 142:87-95

Williams AL, DeSesso JM (2010) The potential of selected brominated flame retardants to affect neurological development. J Toxicol Environ Health B Crit Rev 13:411-448

Wojtowicz AK, Szychowski KA, Kajta M (2014) PPAR- $\gamma$ agonist GW1929 but not antagonist GW9662 reduces TBBPA-induced 
neurotoxicity in primary neocortical cells. Neurotox Res 25:311-322

Zieminska E, Matyja E, Kozlowska H, Stafiej A, Lazarewicz JW (2006a) Excitotoxic neuronal injury in acute homocysteine neurotoxicity: role of calcium and mitochondrial alterations. Neurochem Int 48:491-497

Zieminska E, Stafiej A, Pitsinos EN, Couladouros EA, Moutsos V, Kozlowska H, Toczylowska B, Lazarewicz JW (2006-2007) Synthetic bastadins modify the activity of ryanodine receptors in cultured cerebellar granule cells. Neurosignals 15:283-292

Zieminska E, Toczylowska B, Stafiej A, Lazarewicz JW (2010) Low molecular weight thiols reduce thimerosal neurotoxicity in vitro: modulation by proteins. Toxicology 276:154-163
Zieminska E, Stafiej A, Toczylowska B, Lazarewicz JW (2012) Synergistic neurotoxicity of oxygen-glucose deprivation and tetrabromobisphenol A in vitro: role of oxidative stress. Pharmacol Rep 64:1166-1178

Zieminska E, Stafiej A, Toczylowska B, Lazarewicz JW (2014) Bastadin 12 and ryanodine reveal similarities between thapsigargin- and terabromobisphenol A-induced intracellular $\mathrm{Ca}^{2+}$ release in cultured cerebellar granule cells. J Physiol Pharmacol 65:679-686

Ziemińska E, Stafiej A, Strużyńska L (2014) The role of the glutamatergic NMDA receptor in nanosilver-evoked neurotoxicity in primary cultures of cerebellar granule cells. Toxicology $315: 38-48$ 